\title{
Federal Target Programs: Targeted Funding of Priorities in Science and Technology
}

\author{
M. A. Murav'eva, STRF.ru, exclusively for Acta Naturae
}

\begin{abstract}
A federal target program (FTP) is one of the most important tools that the government has to create an innovative economy in Russia. In particular, the development of Russian science and technology is currently supported through the "Research and Development in Important Scientific and Technological Areas of Russia, 2007-2012" FTP. Currently, the main governmental client of the program, the Federal Agency for Science and Innovations, is being reorganized, and this FTP will be managed by the Ministry of Education and Science; the essence of the program, however, will not change. Top managers of the Federal Agency for Science and Innovations have told us about the program's structure and management.
\end{abstract}

$\mathrm{F}$ ederal programs are designed to reflect the priorities and goals of the social and economic development of Russia; areas of structural, scientific, and technical policy; the forecasted needs and resources of the country; and the external political and economical environment. All federal programs, although differing in subjects, are similar in their focus on priority areas and targeted funding concept. All programs are approved by the Russian government and reflect the state policy in corresponding areas. The programs are primarily funded from the federal budget (funding from other sources, such as regional budgets and nonbudgetary sources, being much smaller). The system of federal target programs (FTP) is one of research, development, industrial, social-economical, and management procedures with coordinated tasks, resources, and schedules effectively addressing the systemic issues of state, economic, sci- entific, social, and cultural development of Russia. In 2010, 801.7 billion rubles will be spent on 54 FTPs on various topics. This year the level of budget funding of high-tech oriented FTPs will be the same as in 2009: about 250 billion rubles. The Research and Development FTP funding totals 7364.05 million rubles, including 6656.33 million rubles allocated to R\&D. All contracts on FTP projects are competitive.

An FTP for the development of science and technology in Russia has existed since 2002 (from 2002 to 2006, its title was "Research and Development in Important Scientific and Technological Areas"; since 2007 its title has been "Research and Development in Important Scientific and Technological Areas of Russia, 2007-2012"). This is the only program based on scientific and technological priorities. There are five fields: Information and Telecommunication Systems, Industry of Nanosystems and Nanomaterials, Environment Conserva- tion, Living Systems, and Power Engineering and Energy Efficiency.

"The distinctive features of this program are its multidisciplinary nature and the fulfillment of the entire innovation chain from the generation of IP to its commercialization," reports Sergey Mazurenko, the head of the Federal Agency for Science and Innovations (Rosnauka). "For the first time, a national program comprises an entire innovation chain and the tasks are set to develop the research and innovation infrastructure. Currently, research and educational institutions and, most importantly, small and mid-sized businesses have demonstrated significant achievements within this program. It is obvious that, if we do not develop innovative businesses and innovative economics, we will reach a dead end; oil and gas tend to run out."

Originally the program was designed to perfect the partnership between private parties and the state, says Alexander Klimenko, deputy head of Rosnauka. To do that, at every stage of the innovation chain, the program requires nonbudgetary funding from those organizations that will commercialize the results. "With this program, the state offers a hand to the business, inviting it to work together on the search, establishment, and development of innovative technologies," concludes Klimenko.

The current management structure and ideology of the FTP formed in 2004, when a Government Decree was issued which substantially changed the preceding 2002-2006 "Research and Development in Important Scientific and Technologial Areas" program. At the beginning, the FTP would often work as a number of uncoordinated projects, 


\section{EXPERTS' OPINIONS}

Sergey K. Vartapetov, PhD (Physics and Mathematics), director of the Center for Instrument Engineering at the Prokhorov Institute of General Physics, Russian Academy of Sciences

As one of the "Research and Development" FTP participants, do you believe this program is an effective tool for the support and development of science?

I believe that the FTP a very effective tool, but there are defects in every tool; therefore, this system has to be further improved and perfected. Let us assume the program intends quick commercialization of the results. This does not take into account the specific character of the "Living Systems" projects. One cannot begin the commercialization of medical equipment or pharmaceuticals 2-3 years after the start of the project. Medical, clinical, and technical tests must be performed, and they require time, too. Now the FTP is designed in such a way that immediately after the R\&D phase one has to begin the commercialization phase. That is not right. We should correct this misunderstanding. If a research team begins commercialization right after the end of the project, I can tell you for sure they have proposed an existing development for the FTP.

Two to three years are needed to develop a high-tech product; in the case of medical devices, at least 12-18 additional months are required for testing. Thus, the development cycle of a new medical product is about 5 years. The FTP deficiency is that these specifics are not taken into account in the program, hence the discrepancy between the requirements and obligations of the contractor.

How in principle should the state support science: where should it stand aside and where should it be active?

I think the answer to this question is clear. As in the rest of the world, the state should provide most funding to the R\&D phases, especially high-risk ones. On the other hand, the state should stand aside at the commercialization phase. The Russian government is reluctant to do that; it seems expensive for the government. Many regulatory issues remain unsettled. The FTP provides that both the state and the author have the right to commercialize, but when two parties own the rights, no one owns them.

I have asked lawyers a number of times if I, as an author, can transfer the rights to an invention to a third party or should I ask the government for release? Whom exactly in the government should I talk to? There has been no answer.

The state has to launch a project in order to create jobs and manufacture machines. However, in fact the state acts as a businessman who has developed something and now wants to sell it. The state should not sell.

Besides creating a lot of confusion with legal issues, commercialization requires a large amount of money. If one secured funding for the R\&D phase and it was successful, one would have to spend ten times more on commercialization to build manufacturing capabilities, enter the market, provide customer service, advertise, etc.

To raise money, one needs to tell the potential investors about his technology and who owns it. When I showed inves- tors what is written in my government contracts, they become confuzed. Businessmen will not risk getting involved in commercialization under uncertain conditions.

Prof. Valery N. Danilenko, Doctor of Science (Biology); Head of the Department of Genetic Foundations of Biotechnology in the Vavilov Institute of General Genetics, Russian Academy of Sciences; and Secretary of the Council at the General Committee of the Russian Academy of Sciences for coordinating research in the "Medical Equipment, Technologies and Pharmaceuticals" area.

What do you think about the effectiveness of the "Research and Development" FTP as a tool for the support and development of science?

This program, especially making "Living Systems" a priority, is a very timely step. The FTP has made a significant contribution to the development of science in Russia. Without this program, we would not have seen the positive changes in this area occurring in the Academy of Sciences and higher educational institutions.

At the same time, the program does not address many important issues. One of these issues is that some projects funded by the FTP, including so-called integrated projects, ultimately hang in the air. The developed technologies and products are not manufactured, do not enter the market, i.e., there is no continuity, no chain from the basic research to a finished innovative drug or technology. This is because of a lack of integration among the state's departments: there is still poor interaction among the specialized programs of Rosnauka, The Ministry of Public Health and Social Development, and the Ministry of Industry and Trade. In addition, the projects supported by the FTP are not coordinated with those supported by the programs of the Russian Academy of Sciences, RFBR and other foundations.

Finally, when the project topics were created, especially at the first stage of the program, not all of the priorities were chosen well, since there were not enough experts in some areas, for example, in innovative drugs. I must admit our expert community is weak. Another important point: administrative staff should not play major role in project assessment. They should help the well-selected experts work efficiently and the researchers and business interact.

Eventually, within the "Living Systems" area of the "Research and Development" FTP, professional mechanisms of expert review, project progress, and quality monitoring have been formed. In my opinion, experience developed within this program on the infrastructural support, coordination board, and workgroup operation should be actively adopted in other FTP, in particular, in the Ministry of Industry and Trade's "Development of Pharmaceutical and Medical Industry of the Russian Federation until 2020 and Onward" Program.

Speaking strategically about supporting science, where should the state stand aside and where should it be active?

It is obvious that, in order to change Russian science, the state must implement certain policies and provide support. 
Rapid changes are impeded by the conservatism of the existing system and the bad heritage of the nineties. The state needs to take part in setting priorities, creating efficient mechanisms for building those priorities, and in targeted financial support. This work has been initiated. Thus, last year the Presidential Committee on the Modernization and Technical Development of Russian Economy was established. It is important to keep working on the integration of Ministries, Departments, and business; ensure the effective use of innovation capabilities of the Academy of Sciences and the Academy of Medical Sciences; and control the selection and progress of large innovation projects. In his speech to students and at the meeting of the Committee on Modernization in Tomsk, President Medvedev emphasized again the importance of innovations, the active participation of the business in innovations, and the creation of adequate conditions for research work in Russia. I completely agree with the president that a decent salary for scientists is a necessary, but not the most critical, condition for the success of science in Russia.

In general, the approaches and principles claimed when creating research and technological programs are correct. How they are implemented is a different story. Science is an important part of the economic system, scientists are a part of Russian society, and all the problems in the country are present to a certain extent in science. For example, it is mainly bureaucrats again who formed the above mentioned "Development of Pharmaceutical and Medical Industry of the Russian Federation until 2020 and Onwards" FTP, but not the community of scientific experts, which must be involved more actively. Not only should scientific experts should be engaged, but also manufacturers and technologists who understand how this area works. In Russia, like in the rest of the world, in recent years, scientists, technologists and experts have been minimally used in making decisions on innovations and the technological modernization of certain areas, in this particular case in the pharmaceutical industry. Everything was farmed out to so-called new generation managers, often not very professional and not quite ready for certain tasks and projects. The international community is now criticizing that approach.

Irina G. Dezhina, Doctor of Science (Economics) and Head of the Sector for Economics of Science and Innovation Processes at the Institute of World Economy and Foreign Relations, Russian Academy of Sciences.

Government support for the implementation of scientific and technological innovations is one of the main tasks of the "Research and Development in Russia" FTP. Are the mechanisms of the government support plain, transparent, and efficient? Expert Irina Dezhina shared her views.

The areas of development of science and technology that are considered "high priority" were set without the extensive participation of the business community. Was that right?

Those areas are so broadly phrased and in such general terms that one can tailor to them almost any needs. In the United States, for example, instead of areas of high priority, there are critical technologies vitally needed by the government. The business community, however, takes part in creat- ing a list of critical technologies, since private companies are among the contractors developing those technologies for the government.

I think that projects that are beneficial only for business should not be financed from the state budget. The replacement of private funds with governmental funds eventually reduces the investment activity of entrepreneurs. Certainly, business should participate in the selection of projects they want to cofinance; the share of business funds, however, should depend on the type and stage of the project.

What are the international practices of running similar programs; how are they different from ours?

I can tell you about the American Advanced Technology Program (ATP) finished in 2007 . This program supported R\&D performed by companies or consortiums of companies, universities, and/or national laboratories.

There were two basic selection criteria: first, there had to be a high likelihood of creating new technologies, which could result in broad cross-industry applications or in creating new markets, and second, the projects had to be in the early stage of development.

The government and the business shared the costs: consortiums of two or more companies had to finance at least half of the project cost, while large companies had to come up with at least $60 \%$. The remainder was financed by the government, but the funds went to national laboratories only; private contractors could not receive budget funds.

We can see two major differences from FTP here: first, no money from the budget was to be given to private parties and, second, the business shared at least $50 \%$ of project costs with the government, whereas the minimum nonbudgetary investment share in large projects is just $30 \%$.

The progress of ATP projects was regularly monitored, and statistical reports were published. In general, the program had a positive impact on the behavior of American companies: $61 \%$ of them increased spending on R\&D, 67\% increased investment in long-term high-tech projects, and $71 \%$ showed more interest in collaborating with governmental research institutions. What is happening in Russia? FTP has been active for years, and it has been modified a few times. Do we have information available that would show that some mechanisms of cooperation between the government and business used within the program worked better than others? The answer is no, and this creates the impression that it is a rather formal mechanism of distributing budget funds here and now which has not been assessed seriously.

Currently, technological development in Russia is in a miserable state. Engineering Science is still in crisis, the number of engineers working in science is going down. Our funding share in basic research has been stable (14-15\% of total science funding), a large portion has been funded to development (almost 70\%), but a very scarce share to applied research (15$16 \%$; before the collapse of the USSR it was 33\%). This means that, while our applied science is in ruins, only small technological improvements are being made which are not based on real scientific breakthrough results, hence the corresponding state of technologies. 
not meeting the expectations of the level of result integration and program coordination. The state took an active part in increasing the efficiency of the FTP by improving the program implementation mechanisms and changing the management concept from the "control of budget funds" to the "management of results." The new paradigm of state management enriched the FTP with a number of qualitative and quantitative metrics for monitoring and controlling the progress and results.

One key FTP task is to initiate and optimize the mechanism for the competitive funding of research projects. This requires, first of all, creating a community of experts in Russia and perfecting the competition procedures and the examination and funding mechanisms. The new management system divides areas of accountability: the scientific community is responsible for the research part, while the administrative staff is responsible for compliance to formal regulations.

Research teams themselves determine the topics of the future funding opportunities of the Federal Program. The proposed $R \& D$ topics undergo a transparent and democratic review and approval process by workgroups involving reputable scientists. After that, applications are invited and proposals are submitted (by any institutions, regardless of the type of ownership and departmental affiliation) and reviewed by experts.

"When the FTP was launched, after Russian science had suffered for 15-20 years without funding, no one knew of the actual state and capabilities of the research groups or which areas are still alive," explains Andrey Petrov, director of the Government Office of Scientific and Technical FTPs. "Then the program's task was to actively monitor the state of research teams, understand the needs of the business and the nonfinancial sector, and assess the capabilities of the research teams. The first two years of the program were dedicated to this task."

This work resulted in the first "wellfocused landscape of science and technology in Russia" according to Sergey Mazurenko. That is, we now realize the status of various research and de- velopment areas in Russia and the capabilities of those who may commercialize them. The best examples, Mr. Mazurenko believes, are the projects in nano- and biotechnology.

\section{PRIORITY TO LIVING SYSTEMS}

Effective diagnostics, agricultural crops enriched in vitamins, new drugs and vaccines, and many other technologies belong to living systems. This area has been undergoing a revolutionary development in recent years, being perhaps the most dynamic field of modern natural science. Life sciences have brilliant prospects of application in biology, medicine, agriculture, materials science, etc. This potential to create high technologies and improve the health and quality of life of humans makes living systems one of the key government priorities in science and technology, and it is actively supported by FTPs, including the "Research and Development" FTP.

"Living Systems," a priority area of the FTP, is generously supported by the state, receiving more than $30 \%$ of the total funds of the program (2.8 billion rubles in 2009), being second in funding only to "Industry of Nanosystems and Nanomaterials" (41.4\% of the total FTP funding, 3.8 billion rubles) but still first in the importance of its results.

Today, living systems attract the attention of scientists all around the world. This field is at the forefront of science, bringing together biologists, chemists, physicists, and mathematicians. Many experts believe that it is living systems that will become the foundation of the new technological revolution, the basis for the new technological way of living. Therefore, the large number of participants in the "Living Systems" area does not look surprising. In 2007, 717 proposals were submitted $(13.6 \%$ of the total number of proposals), 284 contracts were signed with a total budget of over 2.6 billion rubles. In 2008, 939 proposals were submitted to "Living Systems" and 179 contracts were signed (reaching 731 in total together with continuing contracts). In 2009, work was being performed within 282 projects, including 225 projects on basic research in life sciences and technology development, performed by institutions of various ownership types and departmental affiliations from seven regions of Russia.

"We support the most interesting and promising projects," says Inna Bilenkina, deputy head of Rosnauka. "Russian scientists have made a good start; there are strong research teams capable of creating effective drugs and advanced medical equipment. The problem is that these developments have not been actively sought by business yet. In my opinion, overcoming the barrier between basic science and industry is a vital task."

The program has been seriously criticized, in particular, for the mismatch between the research carried out and the needs of industry. Rosnauka admits that this is a problem and is addressing it.

"The topics proposed by scientists do not always push the frontiers," thinks Gennady Shepelev, head of the Department of Programs and Projects of Rosnauka. "It is easier for scientists to request funding for something they already know well and will surely achieve and, as a result, get money for without much effort. I suggest that, instead of using topics proposed by scientists, we invite proposals addressing real business tasks supported by the industry."

Inna Bilenkina thinks that, ideally, there should be two parallel ways of managing the program. The first would be to let the scientific community set the topics, and the second would be to create specific tasks set by the government.

Since 2009, part of the FTP funding has been spent on targeted contracts. Last year, a quarter of the total funding of the program was spent on 50 targeted projects. It had been planned to spend half the money on targeted projects in 2010-2011 and in 2012-2013 allocate $75 \%$ to large tasks combining a few dozen projects.

However, $70 \%$ of the funding for the 2010 program was cut back, which made it impossible to fulfill those plans without jeopardizing three-year projects that started in 2008 and were to continue in 2010. Nevertheless, as Andrey Petrov confirms, Rosnauka will keep launching large centralized tasks, so to speak, to create governmental contracts aimed at ambitious goals. 


\section{ADDITIONAL INFORMATION}

The "Research and Development in Important Scientific and Technological Areas in Russia, 2007-2012" FTP is a continuation of the analogous 2002-2006 Program.

The Ministry of Science and Education of the Russian Federation as a customer and coordinator of the FTP sets the rules of the game (provisions about the program and the management structure, as well as procedures for evaluating and accepting work). Rosnauka is the main government customer; it manages budget funds on the government's behalf, accepts proposals for the FTP topics, and conducts their preliminary evaluation.

This program is managed by the Scientific Coordination Board led by the Minister of Education. This board establishes the schedule and amount of funding of projects and organizes expert groups in priority areas. The groups are made of qualified experts in the areas, representatives of various departments, scientists, businessmen, and technologists. There are more than 2000 experts in total. The aim of the expert groups is to help the board create topics based on proposals from the scientific community. The proposed topics are assessed for their relevance, originality, and scientific importance of possible results. The group members analyze the anticipated results, compare the funding requested to the amount of work proposed, and make a decision about initiating the project. Then Rosnauka holds competitive tenders and awards government contracts.

The activity units of the FTP structural elements:

(i) "Generation of Knowledge"

(ii) "Development of Technologies"

(iii) "Commercialization of Technologies"

(iv) "Institutional Basis for Research and Development"

(v) "Infrastructure of the Innovative System"

Research and development in living systems and the commercialization of the results is carried out in many projects within various units and activities of the FTP:

(1) Unit 1, Activity 1.2 "Perform problem-targeted exploratory research and accumulate scientific and technical knowledge in technologies of living systems": 1-2 year projects with annual funding of up to 10 million rubles per project. The project results must have sound market potential.

(2) Unit 2, Activity 2.2 "Perform integrated projects, including the development of competitive technologies in living systems intended for future commercialisation": 2-3 year projects, including experimental and process development with annual funding of up to 100 million rubles per project and a nonbudgetary funding share of at least $25 \%$.

The integrated project result must have a significant potential for commercialization, and the government contractor is often obliged to utilize the result in its business activities.

(3) Unit 2, Activity 2.7 "Perform experimental and process development jointly with foreign research organizations or in areas proposed by the business community": annual funding of up to 50 million rubles per project and nonbudgetary funding share of at least $50 \%$. The project result must meet the requirements of the business that initiated the project, or the result must be achieved with the direct participation of a foreign research organization, but it must be commercialized strictly in Russia.

(4) Unit 3, Activity 3.2 "Perform technology commercialization projects on topics proposed by the business community": innovation projects including R\&D, manufacturing, and sales of hightech products.

This category is similar to the previous one, but it differs in the scale and clear orientation towards the commercialization of the results. Projects of this type can be initiated by high-tech industrial organizations of any corporate form and type of ownership, as well as innovative industrial companies jointly with research and educational organizations. The government partly finances the R\&D phase of these projects, while other costs (preproduction, advertising, marketing, etc.) are paid by the business.

The project term is up to 3 years, and the annual budget funding reaches 100 million rubles per project, with at least $70 \%$ of additional funding from nonbudgetary sources.

(5) Unit 3, Activity 3.1 "Perform nationally vital innovative projects (VIP) in the high-priority areas of the program": large innovative projects that will provide the following:

(i) The required level of national security,

(ii) Economic impact important for the entire economy, as well as for large economy sectors,

(iii) Solutions to key social issues, first of all, to increase the quality of life.

Each project will be run from the development of an advanced innovative product with a significant commercialization potential to industrial production and the successful market launch of new high-tech products.

Priority projects are based on partnership and risk sharing between the state and the business community. Budget funding of such a project is $1-2$ billion rubles with at least $60 \%$ of additional nonbudgetary funding. The project term can reach 4 years.

The government contractor is obliged to provide for 5 times more money in revenue on sales of the developed high-tech products than the amount of budget money spent on the project.

Submitted projects must be in the framework of the critical technologies in the "Living Systems" area:

- Cell Technologies,

- Bioengineering Technologies,

- Genome and Postgenome Technologies for Drug Development,

- Biocatalysis, Biosynthesis, and Biosensor Technologies,

- Biomedical and Veterinary Technologies for Human and Animal Life Support and Protection.

Program funding by areas

\begin{tabular}{|c|c|c|c|c|c|c|}
\hline & $\begin{array}{l}\text { Budgetary } \\
\text { funding in } \\
2007 \text { (million } \\
\text { rubles) }\end{array}$ & $\begin{array}{c}\text { Budgetary } \\
\text { funding share (\%) }\end{array}$ & $\begin{array}{l}\text { Budgetary } \\
\text { funding in } \\
2008 \text { (million } \\
\text { rubles) }\end{array}$ & $\begin{array}{c}\text { Budgetary } \\
\text { funding share }(\%)\end{array}$ & $\begin{array}{l}\text { Budgetary } \\
\text { funding in } \\
2009 \text { (million } \\
\text { rubles) }\end{array}$ & $\begin{array}{l}\text { Budgetary } \\
\text { funding share }(\%)\end{array}$ \\
\hline Living Systems & 2657.88 & 25.10 & 3242.63 & 24.50 & 2836.95 & 30.32 \\
\hline $\begin{array}{c}\text { Information and Telecommunication } \\
\text { Systems }\end{array}$ & 840.959 & 7.94 & 1161.17 & 8.77 & 734.18 & 7.85 \\
\hline
\end{tabular}

Expenditure from the federal budget on Rosnauka in 2004-2009 